\title{
Quality and antioxidant properties of wheat cookies supplemented with maqui berry powder
}

\author{
Hye Ju Jeon, Jun Ho Lee* \\ Department of Food Engineering, Daegu University, Gyeongsan 38453, Korea
}

\begin{abstract}
Wheat-based products have been supplemented with various health-promoting ingredients to improve their overall qualities. Maqui berries are one of the healthiest benies in nature; however, their use in cookie making has not been reported. Herein, we aimed to develop functionally and nutritionally improved wheat cookies by partially replacing white wheat flour with maqui berry powder (MBP). We prepared cookies supplemented with different MBP concentrations $(2.5 \%, 5 \%, 7.5 \%$, and $10 \%$ ) and compared their quality characteristics and antioxidant activities with those of control cookies (100\% wheat flour without MBP addition). The incorporation of MBP significantly affected the physicochemical parameters of cookie dough and cookies. Specifically, MBP supplementation significantly decreased the $\mathbf{p H}$, while slightly decreasing the density of cookie dough $(\mathrm{p}<0.05)$. The cookie spread factor increased; however, the hardness decreased significantly as the MBP concentration increased $(p<0.05)$. No significant changes in loss rates were observed upon MBP supplementation ( $>>0.05)$. Regarding the color of the cookie surface, $L^{*}$ and $b^{*}$ values significantly decreased, while the $a^{*}$ value increased with the addition of MBP $(p<0.05)$. The 2,2-Diphenyl-1-picrylhydrazyl and 2,2'-azino-bis-3-ethylbenzthiazoline-6-sulphonic acid radical scavenging activities were significantly increased $(\mathbf{p}<\mathbf{0 . 0 5})$ as the concentration of MBP increased, and both activities were well correlated. Hedonic sensory results indicated that cookies supplemented with 7.5\% MBP generally received satisfactory acceptance scores. Overall, the analysis indicated that cookies with acceptable physical characteristics and improved antioxidant activities can be produced by partially replacing wheat flour with MBP. Thus, the addition of MBP to cookies may be a valuable strategy to increase the consumption of health-promoting ingredients in a diet that includes convenience foods.
\end{abstract}

Key words : maqui berry powder, wheat cookie, physicochemical properties, consumer acceptance, antioxidant properties

\section{Introduction}

Bioactive compounds with health-promoting properties are of utmost importance for the food and pharmaceutical industries. Antioxidant compounds delay the oxidation process, inhibiting chain-reaction polymerization and subsequent oxidizing reactions (Halliwell and Aruoma, 1991). Berry fruits have recently gained attention because of their attractive flavor and diverse health-promoting components, including dietary fiber, phenolic acids, flavonoids, vitamins, and minerals (Antoniewska et al., 2019; Ruiz et al., 2013).

Maqui (Aristotelia chilensis L.) is a common edible berry that belongs to the Elaeocarpaceae family, which is grown in central and southern Chile. Maqui berry contains high amounts of anthocyanins, which are a good source of natural colorants (Genskowsky et al., 2015; Girones-Vilaplana et al., 2014). The fruit has been reported as one of the healthiest berries in nature because of its bioactive components (Nakamura et al., 2014; Schreckinger et al., 2010). Several studies have linked the phenolics of maqui berries with their

*Corresponding author. E-mail : leejun@daegu.ac.kr, Phone : +82-53-850-6531, Fax : +82-53-850-6539

Received 14 April 2021; Revised 13 June 2021; Accepted 21 June 2021.

Copyright (c) The Korean Society of Food Preservation.

This is an Open Access article distributed under the terms of the Creative Commons Attribution Non-Commercial License (http://creativecommons.org/licenses/by-nc/4.0) which permits unrestricted non-commercial use, distribution, and reproduction in any medium, provided the original work is properly cited. 
high antioxidant capacity (Girones-Vilaplana et al., 2012; Romero-Gonzalez et al., 2020), digestive enzyme inhibition potential (Bastias-Montes et al., 2020), antidepressant effects (Di Lorenzo et al., 2019), cardioprotection (Cespedes et al., 2008), and in vitro and in vivo anti-diabetic effects (Rojo et al., 2012). Maqui berries have recently gained more popularity than any other berry (Brauch et al., 2016); however, their application in food product development is scarce.

In the cookies industry, several functional ingredients have been incorporated into cookies to improve their overall quality, including sensory properties. Cookies generally contain wheat flour, sugar, and fat with a low final moisture content of $<20 \%$ (wet basis) (Cappa et al., 2020). Cookies are one of the most popular and widely consumed bakery products worldwide owing to their affordable cost, taste, convenience, and relatively longer shelf life (Wang et al., 2014). They can easily provide a good source of energy and refreshment in the form of ready-to-eat convenience food (Park et al., 2017) and are a valuable supplementation vehicle for nutritional improvement (Zucco et al., 2011). Thus, adding berry powder to cookies could be a promising strategy to increase the consumption of healthy ingredients in a diet that includes convenience foods (Klopsch et al., 2019).

Rapidly growing concerns about healthy diets have led to the study of wheat-based products supplemented with various berry powders as new natural value-added food ingredients. Cookies with these characteristics have been produced from the blends of wheat and powders of strawberry (Lee and Kim, 2009), blueberry (Ji and Yoo, 2010; Kim et al., 2014), acai berry (Choi et al., 2014), and cranberry (Choi and Lee, 2015) powders; however, there is no information on the use of maqui berry powder (MBP) in cookie making. In this study, we aimed to assess the suitability of MBP for improving the quality and antioxidant properties of cookies.

\section{Materials and methods}

\section{Materials}

Freeze-dried organic MBP was obtained from Sandlehae (Ham Yang, Korea), while wheat flour (soft flour, CJ Cheiljedang, Yangsan, Korea), white sugar (CJ Cheiljedang, Seoul, Korea), salt-free butter (Lotte Food Co., Cheonan, Korea), and eggs were purchased from a local market.

\section{Cookie formulation and preparation}

The standard cookie (control) recipe comprised of $200 \mathrm{~g}$ $(100 \%)$ of white wheat flour, $90 \mathrm{~g}$ salt-free butter, $100 \mathrm{~g}$ white granulated sugar, and $50 \mathrm{~g}$ eggs. Composite flour cookies were prepared by combining white wheat flour and MBP in ratios of 97.5:2.5, 95:5, 92.5:7.5, and 90:10. Butter, sugar, and eggs were creamed using a kitchen mixer (5K5SS, KitchenAid Inc., St. Joseph, MI, USA) at speed 2 for $2 \mathrm{~min}$ and scraped down every minute. Afterward, wheat flour and MBP were added and mixed at speed 2 for $3 \mathrm{~min}$. The dough was placed in a refrigerator at $4^{\circ} \mathrm{C}$ for $30 \mathrm{~min}$ before sheeting. To prepare the cookies, the dough was slightly flattened with the palm of the hand, sheeted with a roller to a uniform thickness of $4 \mathrm{~mm}$, and cut into circular shapes with a diameter of $5 \mathrm{~cm}$. Then, the dough pieces were placed on a baking tray with baking paper and baked at $170^{\circ} \mathrm{C}$ for $7 \mathrm{~min}$ in a preheated oven $(\mathrm{KXS}-4 \mathrm{G}+\mathrm{H}$, Salvia industrial S.A., Lezo, Spain). Baked cookies were removed from the oven and cooled for $1 \mathrm{~h}$ at room temperature before the analyses were conducted. The test cookie samples containing $0 \%, 2.5 \%, 5 \%, 7.5 \%$, and $10 \%$ MBP were designated as control, MBP2.5, MBP5, MBP7.5, and MBP10, respectively.

\section{Physicochemical analyses of cookie dough and cookies}

A dough sample $(c a .5 \mathrm{~g}$ ) was mixed with $45 \mathrm{~mL}$ of distilled water and vortexed for $1 \mathrm{~min}$. The mixture was held at room temperature for $1 \mathrm{~h}$ to separate the solid and liquid phases. The $\mathrm{pH}$ of the supernatant was measured using a $\mathrm{pH}$ meter (pH/Ion 510, Oakton Instruments, Vernon Hills, IL, USA). Dough density measurements were performed in a $30 \mathrm{~mL}$ mass cylinder by water displacement (Kim and Chung, 2017; Lee et al., 2017).

The cookie spread factor was determined according to AACC Method 10-50D (AACC, 2000). The diameter was measured using a Vernier caliper by laying down six cookies edge to edge. The diameters of the six cookies were measured again after rotating each cookie $90^{\circ}$, and then the average diameter was calculated. Six cookies were stacked on each other, and their thicknesses were measured. Afterward, cookies were restacked in random order, the thickness was measured again, and the average thickness was calculated. The spread factor of cookies was calculated 
by dividing the average diameter of cookies by the average thickness. The loss rate was expressed as a percentage of the weight ratio before and after baking. The moisture content of the cookie was obtained by drying a specific amount $\left(\mathrm{ca} .5 \mathrm{~g}\right.$ ) of the sample to a constant weight at $105^{\circ} \mathrm{C}$ in an oven (FOL-2, Jeio Tech Co., Daejeon, Korea), and the results were reported on a wet basis (w.b.).

The hardness of the baked cookies was measured using a texture analyzer (LRXPlus, Lloyd Instrument Limited, Fareham, Hampshire, UK) in a compression mode via the 3-point bending test using a 3-point bending rig, trigger force of $0.05 \mathrm{~N}$, and load cell of $100 \mathrm{~N}$. The textural studies were conducted at a test speed of $1.0 \mathrm{~mm} / \mathrm{s}$ and a distance $10 \mathrm{~mm}$, and the distance between the two bottom supports was adjusted to $40 \mathrm{~mm}$. The peak value of the fracture force (maximum) was recorded as the hardness at a point when the cookies were broken into two major pieces (Chakraborty et al., 2009). The peak force to snap the cookies was reported as the fracture force in N. Surface color measurement was carried out based on the CIELAB L*, $a^{*}$, and $\mathrm{b}^{*}$ color system using a spectrophotometer (CM-600d, Minolta Co., Osaka, Japan).

\section{Determination of free radical scavenging activities}

The 2,2-Diphenyl-1-picrylhydrazyl (DPPH) radical scavenging activities of the samples were measured in terms of their hydrogen-donating or radical scavenging activities using stable DPPH radicals. The assay was performed as previously described by Blois (1958) with some modifications. Briefly, a $0.15 \mathrm{mM}$ solution of DPPH radical in ethanol was prepared, after which $5 \mathrm{~mL}$ of this solution was added to $1 \mathrm{~mL}$ of the sample solution in ethanol at different concentrations, shaken, and left to stand for $10 \mathrm{~min}$. The decolorization of DPPH-donated protons was determined by measuring the absorbance at $517 \mathrm{~nm}$ using a spectrophotometer (Optizen 2020 UV Plus, Mecasys Co., Ltd., Daejeon, Korea).

The spectrophotometric analysis of 2,2'-azino-bis-3ethylbenzthiazoline-6-sulphonic acid (ABTS) ${ }^{+}$radical scavenging activity was performed according to the method described by Re et al. (1999), with slight modifications. The ABTS cation radical was produced via a reaction between $7.4 \mathrm{mM}$ ABTS in $\mathrm{H}_{2} \mathrm{O}$ and $2.6 \mathrm{mM}$ potassium persulfate during storage in the dark at room temperature for $12 \mathrm{~h}$. Before use, the $\mathrm{ABTS}^{+}$solution was diluted with methanol to obtain an absorbance of 1.1 at $734 \mathrm{~nm}$. Subsequently, $3 \mathrm{~mL}$ of $\mathrm{ABTS}^{+}$solution was added to $0.1 \mathrm{~mL}$ of the sample. After $10 \mathrm{~min}$, the percent inhibition at $734 \mathrm{~nm}$ was calculated for each concentration relative to the blank absorbance. The scavenging activities of DPPH and $\mathrm{ABTS}^{+}$radicals were calculated using the following equation:

Radical scavenging activity $(\%)=$

$$
\left[\left(\text { Abs. control }- \text { Abs. }_{\text {sample }}\right) / \text { Abs. control }\right] \times 100
$$

\section{Sensory evaluation}

Cookies were subjected to sensory evaluation using 50 untrained volunteer panelists (14 males and 36 females, aged 20 to 30), drawn within the university community. Cookies were evaluated for color, flavor, softness, taste, and overall acceptance. The ratings were carried out on a 9-point hedonic scale ranging from 9 (like extremely) to 1 (dislike extremely). The order of serving was randomized. Overall acceptance was evaluated first, and another session was held to evaluate the remaining attributes. An inter-stimulus interval of $30 \mathrm{~s}$ was imposed between the samples to allow time for recovery from adaptation. Participants were advised to rinse their palates between the samples. Sufficient space was provided to handle the samples and questionnaires, and the evaluation time was not constrained. No specific compensation was provided to the participants. This study was approved by the Daegu University Institutional Review Board (IRB \#1040621-201703-HR-011- 02).

\section{Statistical analysis}

Each measurement was conducted in triplicate, except for color $(n=9)$, hardness $(n=15)$, and sensory evaluation $(n=50)$. The experimental data were subjected to analysis of variance (ANOVA) using the general linear model (GLM) procedure to identify significant differences among the samples. The mean values were compared using Duncan's multiple range test. The significance level was set at $5 \%$.

\section{Results and discussion}

\section{Physicochemical characteristics of cookie dough}

Table 1 lists the physicochemical characteristics of cookie dough supplemented with different levels of MBP. The $\mathrm{pH}$ 
Table 1. Physicochemical characteristics of cookie dough containing different levels of MBP

\begin{tabular}{ccc}
\hline \multirow{2}{*}{ Sample $(\%)$} & \multicolumn{2}{c}{ Property } \\
\cline { 2 - 3 } & $\mathrm{pH}$ & Density $(\mathrm{g} / \mathrm{mL})$ \\
\hline 0 & $6.83 \pm 0.12^{\mathrm{a} 1)}$ & $1.24 \pm 0.02^{\mathrm{a}}$ \\
2.5 & $6.07 \pm 0.06^{\mathrm{b}}$ & $1.23 \pm 0.02^{\mathrm{ab}}$ \\
5 & $5.60 \pm 0.00^{\mathrm{c}}$ & $1.22 \pm 0.00^{\mathrm{ab}}$ \\
7.5 & $5.17 \pm 0.06^{\mathrm{d}}$ & $1.21 \pm 0.02^{\mathrm{ab}}$ \\
10 & $4.93 \pm 0.06^{\mathrm{e}}$ & $1.20 \pm 0.02^{\mathrm{b}}$ \\
\hline
\end{tabular}

${ }^{1)}$ Means within the same row without a common letter $\left({ }^{\mathrm{a}-\mathrm{e}}\right)$ are significantly different $(\mathrm{p}<0.05)$.

ranged from 4.93 to 6.83 (range=1.9) and significantly decreased upon the addition of MBP $(\mathrm{p}<0.05)$. Rather drastic changes were observed, presumably due to the strongly acidic nature of MBP. Thus, it seems that MBP supplementation could result in the production of cookies with considerably lower $\mathrm{pH}$ depending on the level of supplementation. A similar reduction in $\mathrm{pH}$ was observed for cookies containing blueberry powder (Ji and Yoo, 2010), acai berry powder (Choi et al., 2014), and cranberry powder (Choi and Lee, 2015). Berries generally contain various organic acids and sugars, and possess strong acidic characteristics in general. The $\mathrm{pH}$ of MBP was reported to be 3.92 (Lee, 2020a).

The density of cookie dough appeared to decrease slightly upon the addition of MBP; nevertheless, minor changes were observed, and only significant differences were found between the control and MBP10 (range $=0.04)(p<0.05)$. The changes in the dough density could be attributed to the interaction between wheat flour protein and the cellulose contained in MBP (Seong et al., 2017); however, the effect was minimal. A similar minimal effect was also reported for cookies supplemented with different levels of black sesame powder (up to $8 \%, \mathrm{w} / \mathrm{w}$ ), whose density ranged from 1.24 to $1.26 \mathrm{~kg} / \mathrm{L}$ (Lim and Lee, 2015).

\section{Physicochemical characteristics of cookies}

Table 2 presents the physicochemical characteristics of cookies supplemented with different levels of MBP. The spread of cookies is an indicator of how the dough is pushed outward during the baking process, resulting in reduced thickness and increased diameter (Lee, 2020b). The spread factor has been widely used as a cookie quality indicator, and spread of cookies is a relatively complex phenomenon influenced by various factors (Pareyt et al., 2009), including the type and absorption of flour, the type and addition of fat and sugar, the kneading time and method, and baking time and temperature (Koh and Noh, 1997).

As the substitution level of white wheat flour increased, the spread factor increased significantly from 8.64 to 11.13 $(p<0.05)$. Compared to control samples, the spread factor of MBP10 samples was significantly different $(p<0.05)$, whereas that of MBP2.5, MBP5, and MBP7.5 samples was not $(p>0.05)$. Similarly, the differences between MBP7.5 and MBP10 were not significantly different $(p>0.05)$. The increase in the spread factor from 8.64 to 11.13 supported previous studies on cookies containing cranberry and black sesame powder (Choi and Lee, 2015; Lim and Lee, 2015). This could be attributed to the impact of wheat gluten and maqui berry fiber on dough formulation (Oladunjoye et al., 2021). The reduction in gluten formation as the wheat flour is substituted by MBP may lead to the increase in the spread

Table 2. Physicochemical characteristics of cookies containing different levels of MBP

\begin{tabular}{ccccc}
\hline \multirow{2}{*}{ Sample (\%) } & \multicolumn{3}{c}{ Property } \\
\cline { 2 - 5 } & Spread factor & Loss rate (\%) & Moisture content (\%, w.b.) & Hardness (N) \\
\hline 0 & $8.64 \pm 0.33^{\mathrm{cl})}$ & $12.68 \pm 0.87^{\mathrm{a}}$ & $5.69 \pm 0.31^{\mathrm{a}}$ & $22.87 \pm 6.12^{\mathrm{a}}$ \\
2.5 & $10.17 \pm 0.32^{\mathrm{b}}$ & $13.01 \pm 1.00^{\mathrm{a}}$ & $5.14 \pm 0.58^{\mathrm{ab}}$ & $14.34 \pm 3.11^{\mathrm{b}}$ \\
5 & $10.35 \pm 0.53^{\mathrm{b}}$ & $13.02 \pm 0.48^{\mathrm{a}}$ & $4.77 \pm 0.68^{\mathrm{ab}}$ & $13.89 \pm 2.73^{\mathrm{b}}$ \\
7.5 & $10.53 \pm 0.33^{\mathrm{ab}}$ & $13.20 \pm 0.92^{\mathrm{a}}$ & $4.64 \pm 0.98^{\mathrm{ab}}$ & $11.95 \pm 4.39^{\mathrm{b}}$ \\
10 & $11.13 \pm 0.41^{\mathrm{a}}$ & $13.22 \pm 0.21^{\mathrm{a}}$ & $3.62 \pm 1.09^{\mathrm{b}}$ & $11.69 \pm 3.16^{\mathrm{b}}$ \\
\hline
\end{tabular}

\footnotetext{
${ }^{1)}$ Means within the same row without a common letter $\left({ }^{\mathrm{a}-\mathrm{c}}\right)$ are significantly different $(\mathrm{p}<0.05)$.
} 
factor (Choi and Lee, 2015; Lim and Lee, 2015), consequently influencing the hardness of the cookies.

The loss rate likely increased slightly with increasing amounts of MBP; however, there was no significant difference among all samples ( $p>0.05$ ). This slight increase is probably due to the increase in the spread factor resulting from the introduction of MBP as the increase in surface area allows for more feasible moisture evaporation during the baking process inside the oven (Lim et al., 2009). Lim and Lee (2015) replaced wheat flour with black sesame powder in cookies and reported similar trends for substitution between $2 \%$ and $8 \%(13.43-15.10)$.

The moisture content of cookies ranged from 3.62 to $5.69 \%$ (w.b.) and decreased significantly upon the addition of MBP $(\mathrm{p}<0.05)$, with no significant differences among MBP2.5, MBP5, and MBP7.5 samples ( $>>0.05)$. An affinity effect between MBP and moisture likely existed (Lim et al., 2003); however, the overall moisture content obtained in this study was within the acceptable moisture level $(\sim 5 \%)$ of freshly baked cookies to improve keeping quality (Cauvain and Young, 2008).

The hardness of wheat cookies $(22.87 \mathrm{~N})$ was significantly decreased with the addition of MBP $(\mathrm{p}<0.05)$. The hardness values for MBP cookies were in the ragne of those found by others (Choi and Lee, 2015; Lee, 2017). These textural changes indicated that the cookies became softer with increasing concentrations of MBP. The decreased hardness of composite cookies may be due to the limited formation of the gluten dough network during baking (Choi and Lee, 2015; Kang and Lee, 2007). A decrease in the hardness of wheat cookies containing blueberry and cranberry powders has also been reported (Choi and Lee, 2015; Ji and Yoo, 2010). Yang et al. (2020) reported lower hardness values $(10.5-20.0 \mathrm{~N})$ for cookies prepared from wheat malt than those recorded in this study. The variations in cookie hardness may be attributed to the differences in the preparation methods and the amounts of fiber, starch, and protein components included in the partially replaced ingredients (Ji and Yoo, 2010; Oladunjoye et al., 2021).

Regarding color characteristics, the data were expressed as CIELAB L*, a*, and $b^{*}$ values of the cookies obtained from different formulations and are presented in Table 3 and shown in Fig. 1. The $\mathrm{L}^{*}, \mathrm{a}^{*}$, and $\mathrm{b}^{*}$ values correspond to lightness, redness, and yellowness, respectively. The effect

Table 3. Color characteristics of cookies containing different levels of MBP

\begin{tabular}{cccc}
\hline \multirow{2}{*}{ Sample $(\%)$} & \multicolumn{3}{c}{ CIELAB color characteristics } \\
\cline { 2 - 4 } & $\mathrm{L}^{*}$ & $\mathrm{a}^{*}$ & $\mathrm{~b}^{*}$ \\
\hline 0 & $62.53 \pm 0.25^{\mathrm{a} 1)}$ & $5.62 \pm 0.18^{\mathrm{a}}$ & $29.36 \pm 0.30^{\mathrm{a}}$ \\
5 & $35.87 \pm 1.46^{\mathrm{b}}$ & $3.24 \pm 0.57^{\mathrm{d}}$ & $5.18 \pm 0.91^{\mathrm{a}}$ \\
7.5 & $28.65 \pm 2.07^{\mathrm{c}}$ & $4.56 \pm 0.21^{\mathrm{c}}$ & $-0.32 \pm 0.28^{\mathrm{d}}$ \\
10 & $24.72 \pm 1.55^{\mathrm{d}}$ & $4.97 \pm 0.79^{\mathrm{bc}}$ & $-1.74 \pm 0.30^{\mathrm{e}}$ \\
\hline
\end{tabular}

${ }^{1)}$ Means within the same row without a common letter $\left({ }^{\mathrm{a}-\mathrm{e}}\right)$ are significantly different $(\mathrm{p}<0.05)$.

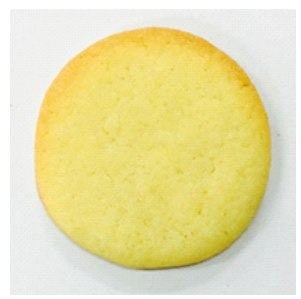

(A)

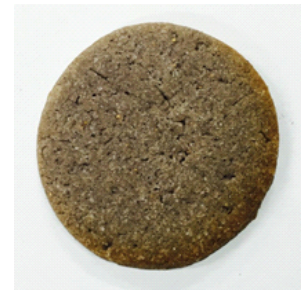

(B)

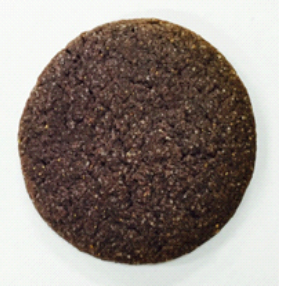

(C)

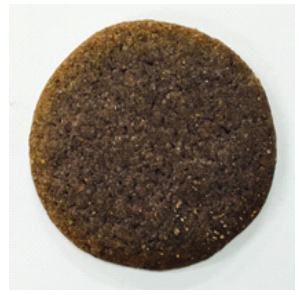

(D)

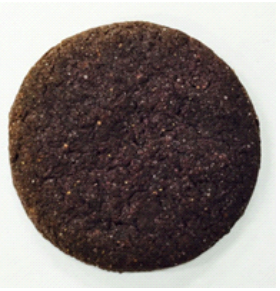

(E)

Fig. 1. Images of cookies with different MBP substitution levels.

A, control; B, 2.5\%; C, 5\%; D, 7.5\%; E, $10 \%$. 
of the addition of different levels of MBP can easily be established by observing the values of control cookies and MBP-added cookies. As the concentration of MBP in the formulation increased, the cookies became darker and browner in color, as evidenced by the lower $L^{*}$ values of MBP-added cookies when compared with control cookies. Control samples exhibited the highest $\mathrm{L}^{*}$ value (62.53), whereas MBP10 samples exhibited the lowest value (21.45). The $\mathrm{a}^{*}$ and $\mathrm{b}^{*}$ values of the MBP-added cookies were lower than those of the control cookies. The $\mathrm{a}^{*}$ value increased, whereas the $b^{*}$ value decreased significantly as the MBP level increased $(\mathrm{p}<0.05)$. These color changes were due to the formation of Maillard browning reactions. The occurrence of a higher degree of Maillard reaction with a high redness surface was probably due to the higher protein and fiber contents in MBP than in wheat flour (Sozer et al., 2014). These results are in accordance with the findings reported for cookies supplemented with different types of berry powders, namely blueberry ( $\mathrm{Ji}$ and Yoo, 2010), cranberry (Choi and Lee, 2015), and acai berry (Choi et al., 2014) as well as wheat malt (Yang et al., 2020).

\section{Radical scavenging activities}

Antioxidant compounds are well known to prevent, delay, or retard rancidity and other flavor deterioration in foods and are capable of protecting the human body from oxidative damage (Jan et al., 2016). The antioxidant activities of control and composite cookies are presented in Fig. 2, which shows that the activity of control samples was

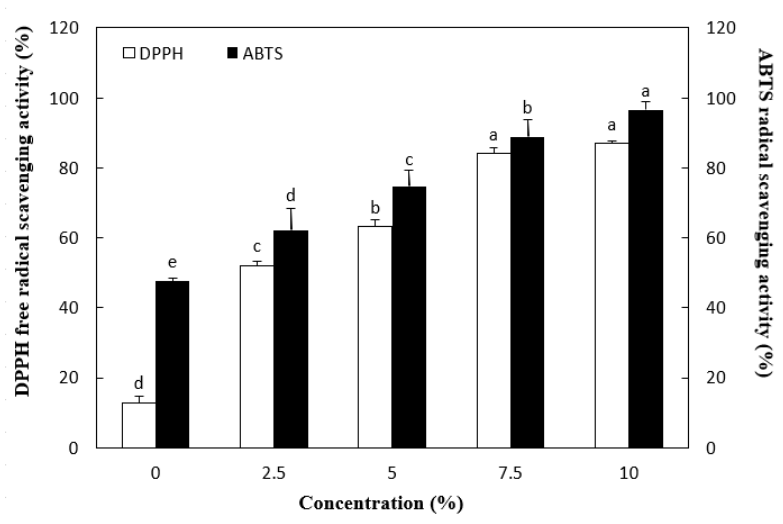

Fig. 2. DPPH and ABTS radical scavenging activities of cookies with different MBP substitution levels.

Means within the same activity without a common letter $\left(^{\mathrm{a}-\mathrm{e}}\right)$ are significantly different $(\mathrm{p}<0.05)$. significantly lower than that of the composite cookies containing MBP $(p<0.05)$. Antioxidant activity increased with increasing concentrations of MBP (control < MBP2.5 < MBP5 < MBP7.5 < MBP10). The highest DPPH and ABTS activities (86.85\% and $94.49 \%$, respectively) were exhibited by cookies containing $10 \%$ MBP. Thie increase could be related to the significant amounts of polyphenols present in MBP (Girones-Vilaplana et al., 2012; Romero-Gonzalez et al., 2020). Cookies supplemented with powders of cranberry (Choi and Lee, 2015), flaxseed (Kaur et al., 2017), pak choi (Lee, 2020b), and wheat-hog plum bagasse (Oladunjoye et al., 2021) have shown a similar increase in the antioxidant activity.

The thermal stability of the antioxidant properties of MBP or any other ingredients during baking is not a concern for the development of these types of value-added cookies. Studies have shown that the antioxidant activities (DPPH and ABTS radical scavenging activities) of selected fruits and vegetables increase as the heating temperature during heat treatment $\left(110,120,130,140\right.$, and $150^{\circ} \mathrm{C}$ for $\left.2 \mathrm{~h}\right)$ increases (Kim et al., 2008). Volf et al. (2014) also reported that exposure of the standard solutions and vegetal extracts exposed to high temperatures (up to $100^{\circ} \mathrm{C}$ for $4 \mathrm{~h}$ ) exhibit relatively stable concentrations of phenolic compounds. Moreover, baking has reportedly increased the antioxidant activity of cookies due to the formation of dark brown color pigments during the baking process (Chauhan et al., 2015). Thus, MBP may be suitable for use as a healthy ingredient in baked cookies to bolster antioxidant content.

\section{Sensory quality of cookies}

The sensory qualities of control cookies were compared to those of composite cookies, and the results are shown in Table 4 . The mean sensory scores of control cookies were 6.88 for color, 6.16 for flavor, 4.94 for softness, 5.38 for taste, and 5.80 for overall acceptability. The sensory panelists rated the control sample with the highest scores for color and flavor. These were closely followed by MBP7.5 samples. Cookies containing MBP at lower concentrations exhibited reduced sensory scores except for softness. However, MBP7.5 cookies obtained the highest or statistically comparable scores for all sensory attributes, including overall acceptability, except for color. Furthermore, MBP addition significantly lowered all sensory scores, except for 
Table 4. Sensory scores of cookies prepared from blends of MBP and wheat flour

\begin{tabular}{clllll}
\hline \multirow{2}{*}{ Sample (\%) } & \multicolumn{3}{c}{ Attribute } \\
\cline { 2 - 6 } & Color & Flavor & Softness & Taste & Overall acceptability \\
\hline 0 & $6.88 \pm 1.62^{\mathrm{al})}$ & $6.16 \pm 1.52^{\mathrm{a}}$ & $4.94 \pm 1.81^{\mathrm{b}}$ & $5.38 \pm 2.01^{\mathrm{bc}}$ & $5.80 \pm 2.10^{\mathrm{b}}$ \\
2.5 & $2.63 \pm 1.63^{\mathrm{d}}$ & $5.08 \pm 1.64^{\mathrm{b}}$ & $5.52 \pm 2.09^{\mathrm{b}}$ & $5.12 \pm 2.02^{\mathrm{c}}$ & $4.48 \pm 2.22^{\mathrm{c}}$ \\
5 & $4.35 \pm 1.55^{\mathrm{c}}$ & $5.38 \pm 1.95^{\mathrm{b}}$ & $4.80 \pm 1.83^{\mathrm{b}}$ & $4.90 \pm 1.83^{\mathrm{c}}$ & $4.96 \pm 1.54^{\mathrm{c}}$ \\
7.5 & $6.10 \pm 1.82^{\mathrm{b}}$ & $5.56 \pm 1.89^{\mathrm{ab}}$ & $6.34 \pm 1.94^{\mathrm{a}}$ & $6.76 \pm 1.71^{\mathrm{a}}$ & $6.70 \pm 1.79^{\mathrm{a}}$ \\
10 & $5.96 \pm 2.02^{\mathrm{b}}$ & $4.92 \pm 2.20^{\mathrm{b}}$ & $5.46 \pm 2.15^{\mathrm{b}}$ & $6.06 \pm 1.88^{\mathrm{ab}}$ & $5.78 \pm 1.84^{\mathrm{b}}$ \\
\hline
\end{tabular}

${ }^{1)}$ Means within the same row without a common letter $\left({ }^{\mathrm{a}-\mathrm{c}}\right)$ are significantly different $(\mathrm{p}<0.05)$.

taste $(\mathrm{p}<0.05)$. On a nine-point hedonic scale, MBP7.5 received mean scores over 6.10, except for flavor (5.56), which seems very acceptable. The best sensory quality for MBP cookies was achieved when the MBP concentration was $7.5 \%$. Considering these results, partial replacement of white wheat flour with $7.5 \% \mathrm{MBP}$ in the cookie formulation seems satisfactory. In a similar study reported by Choi et al. (2014), it was observed that acai berry powder can be incorporated into cookies as a partial replacement for wheat flour at a maximum of $6 \%$, without negatively affecting the physical and sensory quality of the final product.

\section{Acknowledgements}

This research was supported by the Daegu University Grant, 2017.

\section{Conflict of interests}

The authors declare no potential conflict of interest.

\section{ORCID}

Hye Ju Jeon https://orcid.org/0000-0002-2829-6507 Jun Ho Lee https://orcid.org/0000-0002-8718-4791

\section{References}

AACC. Approved Methods of the AACC (10-50D). 10th ed, American Association of Cereal Chemists. St Paul, MN, USA, p 1-6 (2000)

Antoniewska A, Rutkowska J, Pineda MM. Antioxidative, sensory and volatile profiles of cookies enriched with freeze-dried Japanese quince (Chaenomeles japonica) fruits. Food Chem, 286, 376-387 (2019)

Bastias-Montes JM, Monterrosa K, Munoz-Farina O, Garcia O, Acuna-Nelson SM, Martin CVS, Quevedo-Leon R, Kubo I, Avila-Acevedo JG, Domiguez-Lopez M, Wei ZJ, Thakur K, Cespedes-Acuna CL. Chemoprotective and antiobesity effects of tocols from seed oil of maquiberry: Their antioxidative and digestive enzyme inhibition potential. Food Chem Toxicol, 136, 111036 (2020)

Blois MS. Antioxidant determinations by the use of a stable free radical. Nature, 181, 1199-1200 (1958)

Brauch JE, Buchweitz M, Schweiggert RM, Carle R. Detailed analyses of fresh and dried maqui (Aristotelia chilensis (Mol.) Stuntz) berries and juice. Food Chem, 190, 308-316 (2016)

Cappa C, Kelly JD, Ng PKW. Baking performance of 25 edible dry bean powders: Correlation between cookie quality and rapid test indices. Food Chem, 302, 125338 (2020)

Cauvain SP, Young LS. Bakery Food Manufacturer and Quality: Water Control and Effects. Wiley-Blackwell, Hoboken, NJ, USA, p 1-23 (2008)

Cespedes CL, El-Hafidi M, Pavon N, Alarcon J. Antioxidant and cardioprotective activities of phenolic extracts from fruits of Chilean blackberry Aristotelia chilensis (Elaeocarpaceae), Maqui. Food Chem, 107, 820-829 (2008)

Chakraborty SK, Singh DS, Kumbhar BK, Singh D. Process parameter optimization for textural properties of readyto-eat extruded snack food form millet and pulsebrokens blends. J Texture Stud, 40, 710-726 (2009)

Chauhan A, Saxena DC, Singh S. Total dietary fibre and 
antioxidant activity of gluten free cookies made from raw and germinated amaranth (Amaranthus spp.) flour. LWT-Food Sci Technol, 63, 939-945 (2015)

Choi JE, Lee JH. Quality and antioxidant attributes of cookies supplemented with cranberry powder. Korean J Food Sci Technol, 47, 132-135 (2015)

Choi YS, Kim SK, Mo EK. Quality characteristics of cookies with acai berry (Euterpe oleracea Mart.) powder added. Korean J Food Preserv, 21, 661-667 (2014)

Di Lorenzo A, Sobolev AP, Nabavi SF, Sureda A, Moghaddam AH, Khanjani S, Di Giovanni C, Xiao J, Shirooie S, Tsetegho Sokeng AJ, Baldi A, Mannina L, Nabavi SM, Daglia M. Antidepressive effects of a chemically characterized maqui berry extract (Aristotelia chilensis (Molina) Stuntz) in a mouse model of Poststroke depression. Food Chem Toxicol, 129, 434-443 (2019)

Genskowsky E, Puente LA, Perez-Alvarez JA, FernandezLopez J, Munoz LA, Viuda-Martos M. Assessment of antibacterial and antioxidant properties of chitosan edible films incorporated with maqui berry (Aristotelia chilensis). LWT-Food Sci Technol, 64, 1057-1062 (2015)

Girones-Vilapalana A, Baenas N, Villano D, Speisky H,

Garcia-Viguera C, Moreno DA. Evaluation of LatinAmerican fruits rich in phytochemicals with biological effects. J Funct Food, 7, 599-608 (2014)

Girones-Vilapalana A, Mena P, Garcia-Viguera C, Moreno DA. A novel beverage rich in antioxidant phenolics: Maqui berry (Aristotelia chilensis) and lemon juice. LWT-Food Sci Technol, 47, 279-286 (2012)

Halliwell B, Aruoma OI. DNA damage by oxygen-derived species: Its mechanism and measurement in mammalian systems. FEBS Lett, 281, 9-19 (1991)

Jan R, Saxena DC, Singh S. Physico-chemical, textural, sensory and antioxidant characteristics of gluten-free cookies made from raw and germinated Chenopodium (Chenopodium album) flour. LWT-Food Sci Technol, 71, 281-287 (2016)

Ji JR, Yoo SS. Quality characteristics of cookies with varied concentrations of blueberry powder. J East Asian Soc Dietary Life, 20, 433-438 (2010)

Kang NE, Lee IS. Quality characteristics of the sugar cookies with varied levels of resistant starch. Korean J Food Culture, 22, 468-474 (2007)
Kaur M, Singh V, Kaur R. Effect of partial replacement of wheat flour with varying levels of flaxseed flour on physicochemical, antioxidant and sensory characteristics of cookies. Bioact Carbohydr Diet Fibre, 9, 14-20 (2017)

Kim HY, Woo KS, Hwang IG, Lee YR, Jeong HS. Effects of heat treatments on the antioxidant activities of fruits and vegetables. Korean J Food Sci Technol, 40, 166-170 (2008)

Kim K, Liu Y, Yoon L, Park H. Comparison of quality characteristics and antioxidative activities of cookies containing blueberry powder and different types of egg yolk. J Korean Soc Food Sci Nutr, 43, 999-1008 (2014)

Kim MJ, Chung HJ. Quality characteristics and antioxidant activities of rice cookies added with Lentinus edodes powder. Korean J Food Preserv, 24, 421-430 (2017)

Klopsch R, Baldermann S, Hanschen FS, Voss A, Rohn S, Schreiner M, Neugart S. Brassica-enriched wheat bread: Unraveling the impact of ontogeny and breadmaking on bioactive secondary plant metabolites of pak choi and kale. Food Chem, 295, 412-422 (2019)

Koh WB, Noh WS. Effect of sugar particle size and level on cookie spread. J East Asian Soc Diet Life, 7, 159-165 (1997)

Lee JA. Quality characteristics of jeungpyun added with maqui berry powder. Culi Sci Hos Res, 26, 247-256 (2020a)

Lee JH. Physicochemical and sensory evaluation of wheat cookies supplemented with burdock powder. Korean J Food Preserv, 24, 1053-1059 (2017)

Lee JH. Quality and antioxidant properties of wheat cookies supplemented with pak choi powder. Korean J Food Preserv, 27, 487-494 (2020b)

Lee JH, Kim IY. Consumer perception and sensory characteristics of cookies incorporated with strawberry powder. J Food Sci Nutr, 14, 66-70 (2009)

Lee YM, Shin HS, Lee JH. Quality characteristics and antioxidant properties of cookies supplemented with Taraxacum coreanum powder. J Korean Soc Food Sci Nutr, 46, 273-278 (2017)

Lim EJ, Huh CO, Kwon SH, Yi BS, Cho KR, Shin SG, Kim SY, Kim JY. Physical and sensory characteristics of cookies with added leek (Allium tuberosum Rottler) powder. Korean J Food Nutr, 22, 1-7 (2009) 
Lim JA, Lee JH. Quality and antioxidant properties of cookies supplemented with black sesame powder. J Korean Soc Food Sci Nutr, 44, 1058-1063 (2015)

Lim YS, Cha WJ, Lee SK, Kim YJ. Quality characteristics of wet noodles with Lycii fructus powder. Korean J Food Sci Technol, 35, 77-83 (2003)

Nakamura S, Tanaka J, Imada T, Shimoda H, Tsubota K. Delphinidin 3,5-O-diglucoside, a constituent of the maqui berry (Aristotelia chilensis) anthocyanin, restores tear secretion in a rat dry eye model. J Funct Foods, 10, 346-354 (2014)

Oladunjoye AO, Eziama SC, Aderibigbe OR. Proximate composition, physical, sensory and microbial properties of wheat-hog plum bagasse composite cookies. LWTFood Sci Technol, 141, 111038 (2021)

Pareyt B, Talhaoui F, Kerckhofs G, Brijs K, Goesaert H, Wevers M, Delcour JA. The role of sugar and fat in sugar-snap cookies: Structural and textural properties. J Food Eng, 90, 400-408 (2009)

Park BR, Choi JE, Lee JH. Effect of dried Hovenia dulcis fruit powder on quality characteristics and antioxidant properties of cookies. Korean J Food Preserv, 24, 517-523 (2017)

Re R, Pellegrini N, Proteggente A, Pannala A, Yang M, Rice-Evans C. Antioxidant activity applying an improved ABTS radical cation decolorization assay. Free Radical Biol Med, 26, 1231-1237 (1999)

Rojo LE, Ribnicky D, Logendra S, Poulev A, Rojas-Silva P, Khun P, Dorn R, Grace MH, Lila MA, Raskin I. In vitro and in vivo anti-diabetic effects of anothocyanins from maqui berry (Aristotelia chilensis). Food Chem, 131, 387-396 (2012)

Romero-Gonzalez J, Ah-Hen KS, Lemus-Mondaca R, MunozFarina O. Total phenolics, anthocyanin profile and antioxidant activity of maqui, Aristotelia chilensis (Mol.) Stuntz, berries extract in freeze-dried polysaccharides microcapsules. Food Chem, 313, 126115, (2020)

Ruiz A, Hermosin-Gutierrez I, Vergara C, von Baer D, Zapata M, Hitschfeld A, Obando L, Mardones C. Anthocyanin profiles in south Patagonian wild berries by HPLC-DAD-ESI-MS/MS. Food Res Int, 51, 706-713 (2013)

Schreckinger ME, Lotton J, Lila MA, de Mejia EG. Berries from South America: A comprehensive review on chemistry, health potential, and commercialization. J Med Food, 13, 233-246 (2010)

Seong JH, Park HS, Chung HS, Kim DS, Kim HS, Lee YG. Effect of young persimmon fruit powder on rice cookie quality. Korean J Food Preserv, 24, 1060-1066 (2017)

Sozer N, Cicerelli L, Heinio RL, Poutanen K. Effect of wheat bran addition on in vitro starch digestibility, physico-mechanical and sensory properties of biscuits. J Cereal Sci, 60, 105-113 (2014)

Volf I, Ignat I, Neamtu M, Popa VI. Thermal stability, antioxidant activity, and phto-oxidation of natural polyphenols. Chem Pap, 68, 121-129 (2014)

Wang L, Li SL, Gao QY. Effect of resistant starch as dietary fiber substitute on cookies quality evaluation. Food Sci Technol Res, 20, 263-272 (2014)

Yang B, Guo M, Zhao Z. Incorporation of wheat malt into a cookie recipe and its effect on the physicochemical properties of the corresponding dough and cookies. LWT-Food Sci Technol, 117, 108651 (2020)

Zucco F, Borsuk Y, Arntfield SD. Physical and nutritional evaluation of wheat cookies supplemented with pulse flours of different particle sizes. LWT-Food Sci Technol, 44, 2070-2076 (2011) 